\title{
FAKTOR-FAKTOR YANG MEMPENGARUHI KUNJUNGAN LANJUT USIA UNTUK BERKUNJUNG KE POSBINDU TAWANG SARI DI WILAYAH KERJA PUSKESMAS TAWANG KOTA TASIKMALAYA TAHUN 2012.
}

oleh :

H. Aam Nursalam, SKM,MM.Kes

\section{A. Abstrak}

Sekitar $15 \%$ diantaranya mengalami dementia atau pikun, di samping penyakit degeneratif lainnya seperti penyakit kanker, jantung, reumatik, osteoporosis, katarak dan lain-lain. Dementia atau pikun adalah salah satu penyakit yang ditandai gangguan daya pikir dan daya ingat yang bersifat progresif disertai gangguan bahasa, perubahan kepribadian dan perilaku (Sujudi : 2004). Menurut data SKRT (Survey Kesehatan Rumah Tangga) tahun 2007 menunjukkan angka kesakitan penduduk usia 55 tahun ke atas sebesar 25,7 persen. Berdasarkan SKRT tahun 2007 angka kesakitan usia 55 tahun 15,1\%, dan menurut SKRT 20007 angka kesakitan usia 45-59 sebesar 11,6 persen (Wirakartakusumah : 2010).Di Posyandu Tawang Sari hanya ada 7 orang saja yang biasa berkunjung ke Posyandu Lanjut Usia dari 68 orang jumlah lanjut usia di daerah Posyandu Tawang Sari. Hal ini disebabkan kurangnya kemandirian dari lanjut usia dalam faktor kesehatan. Dikarenakan tidak mandirinya lanjut usia maka dalam melakukan aktivitas masih memerlukan bantuan orang lain. Tujuan penelitian ini adalah untuk mengetahui faktor-faktor yang mempengaruhi kunjungan lanjut usia untuk berkunjung ke Posbindu Tawang Sari di Wilayah kerja Puskesmas Tawang Kota Tasikmalaya tahun 2012.

Jenis penelitian ini adalah penelitian kuantitatif, dengan metode deskriptif. Desain penelitian menggunakan pendekatan exploratory study. Populasi penelitian ini adalah seluruh usia lanjut di Posbindu Tawangsari di Wilayah Kerja Puskesmas Tawang Kota Tasikmalaya berjumlah 68 orang lanjut usia. Sampel penelitian ini ditentukan menggunakan teknik total sampling. Instrumen pengumpulan data primer menggunakan kuesioner sebagai pedoman pertanyaan. Analisis data menggunakan analisis univariat dengan menghitung presentase dari masing-masing variabel. Pengambilan kesimpulan hasil penelitian dihitung dari rata-rata presentase penilaian setiap indikator. Hasil penelitian disajikan dalam tabel distribusi frekuensi.

Hasil penelitian menyatakan bahwa 60,3\% pengetahuan lanjut usia tentang Posbindu termasuk kategori cukup , 67,65\% sikap lanjut usia terhadap Posbindu termasuk kategori baik, 100 \% responden menyatakan ketersedianya sarana pelayanan kesehatan di Posbindu termasuk kategori kurang memuaskan serta 100\% Responden menyatakan bahwa Gambaran sikap dan perilaku petugas kesehatan Posbindu termasuk kategori memuaskan.

Kesimpulan menyatakan bahwa 60,3\% pengetahuan lanjut usia tentang Posbindu termasuk kategori cukup , 67,65\% sikap lanjut usia terhadap Posbindu termasuk kategori baik, $100 \%$ responden menyatakan ketersedianya sarana pelayanan kesehatan di Posbindu termasuk kategori kurang memuaskan serta 100\% Responden menyatakan bahwa Gambaran sikap dan perilaku petugas kesehatan Posbindu termasuk kategori memuaskan.. Diharapkan dapat memanfaatkan fasilitas kesehatan sebaik mungkin. Sehingga berkunjung ke posyandu secara tertatur dan rutin ke petugas kesehatan atau tempat pelayanan kesehatan dapat mengetahui kesehatannya.

Kata kunci : Posbindu, lansia, pengetahuan, sikap, fasilitas dan peran petugas 


\section{B. Latar Belakang}

Salah satu hasil dalam upaya pembangunan kesehatan di Indonesia adalah kesehatan. Tetapi di sisi lain merupakan tantangan bagi kita semua untuk dapat mempertahankan kesehatan dan kemandirian para lanjut usia agar tidak menjadi beban bagi dirinya, keluarga maupun masyarakat. Dari jumlah itu sekitar $15 \%$ diantaranya mengalami dementia atau pikun, di samping penyakit degeneratif lainnya seperti penyakit kanker, jantung, reumatik, osteoporosis, katarak dan lainlain. Dementia atau pikun adalah salah satu penyakit yang ditandai gangguan daya pikir dan daya ingat yang bersifat progresif disertai gangguan bahasa, perubahan kepribadian dan perilaku (Sujudi : 2004).

Dari populasi lansia yang tercatat sebanyak 16.522.311 jiwa, sekitar $3.092 .910 \quad(20 \%)$ diantaranya adalah lansia terlantar. Jumlah lansia terlantar yang mendapat pelayanan kesejahteraan sosial pada tahun 2005 adalah sebanyak 15.920 orang, sedangkan pada tahun 2006 bantuan kesejahteraan sosial kepada lansia meningkat menjadi 15.930 orang (Depsos : 2006).

Menurut data SKRT (Survey Kesehatan Rumah Tangga) tahun 2007 menunjukkan angka kesakitan penduduk usia 55 tahun ke atas sebesar 25,7 persen. Berdasarkan SKRT tahun 2007 angka kesakitan usia 55 tahun 15,1\%, dan menurut SKRT 20007 angka kesakitan usia 45-59 sebesar 11,6 persen (Wirakartakusumah : 2010).

Di Posyandu Tawang Sari hanya ada 7 orang saja yang biasa berkunjung ke Posyandu Lanjut Usia dari 68 orang jumlah lanjut usia di daerah Posyandu Tawang Sari. Hal ini disebabkan kurangnya kemandirian dari lanjut usia dalam faktor kesehatan. Dikarenakan tidak mandirinya lanjut usia maka dalam melakukan aktivitas masih memerlukan bantuan orang lain.
Berdasarkan paparan di atas, maka penulis bertujuan untuk mengadakan penelitian mengenai "Faktor-faktor yang mempengaruhi perilaku lanjut usia untuk berkunjung ke Posyandu Tawang Sari di Wilayah Kerja Puskesmas Tawang Kota Tasikmalaya tahun 2012”.

Tujuan penelitian ini adalah untuk mengetahui faktor-faktor yang mempengaruhi kunjungan lanjut usia untuk berkunjung ke Posbindu Tawang Sari di Wilayah kerja Puskesmas Tawang Kota Tasikmalaya tahun 2012.

\section{Metode}

Jenis penelitian ini adalah penelitian kuantitatif, dengan metode deskriptif. Desain penelitian menggunakan pendekatan exploratory study. Populasi penelitian ini adalah seluruh usia lanjut di Posbindu Tawangsari di Wilayah Kerja Puskesmas Tawang Kota Tasikmalaya berjumlah 68 orang lanjut usia. Sampel penelitian ini ditentukan menggunakan teknik total sampling yaitu usia lanjut di Posyandu Tawangsari di Wilayah Kerja Puskesmas Tawang Kota Tasikmalaya pada Bulan April-Mei 2012.

Instrumen pengumpulan data primer menggunakan kuesioner sebagai pedoman pertanyaan untuk mengetahui faktor-faktor yang mempengaruhi perilaku lanjut usia untuk berkunjung ke Posyandu Tawang Sari di Wilayah Kerja Puskesmas Tawang Kota Tasikmalaya.

Pengumpulan data primer dilaksanakan dengan cara membagikan lembar kuesioner, pengisian kuesioner dilakukan oleh responden. Dengan pengawasan langsung oleh peneliti. Sedangkan pengumpulan data sekunder dengan melakukan telaah dokumen untuk mendapatkan data usia lanjut.

Analisis data menggunakan analisis univariat dengan menghitung presentase dari masing-masing variabel. Pengambilan kesimpulan hasil penelitian dihitung dari rata-rata presentase penilaian setiap indikator. Hasil 
penelitian disajikan dalam tabel distribusi frekuensi.

\section{Hasil Penelitian}

1. Umur

Adapun gambaran distribusi frekuensi responden menurut umur dapat dilihat dalam tabel di bawah ini :

Tabel 5.5 Distribusi Frekuensi Menurut Umur

\begin{tabular}{|l|c|c|}
\hline $\begin{array}{c}\text { Umur } \\
\text { (Tahun) }\end{array}$ & $\begin{array}{c}\text { Frekuensi } \\
\text { (Orang) }\end{array}$ & $\mathbf{\%}$ \\
\hline $45-59$ & 45 & 66,18 \\
\hline $60-69$ & 17 & 25 \\
\hline$>70$ & 6 & 8,82 \\
\hline Jumlah & 68 & 100 \\
\hline
\end{tabular}

(Sumber : Penelitian 2012)

Berdasarakan tabel 5.5 di atas, distribusi umur responden paling banyak terdapat pada usia 45-59 tahun yaitu sebanyak 45 orang $(66,18 \%)$, dan umur responden yang paling sedikit terdapat pada usia $>70$ tahun sebanyak 6 orang $(8,82 \%)$.

2. Jenis Kelamin

Adapun gambaran distribusi frekuensi responden menurut jenis kelamin dapat dilihat dalam tabel di bawah ini :

Tabel 5.6 Distribusi Frekuensi Menurut Jenis Kelamin

\begin{tabular}{|l|c|c|}
\hline $\begin{array}{c}\text { Jenis } \\
\text { Kelamin }\end{array}$ & $\begin{array}{c}\text { Frekuensi } \\
\text { (Orang) }\end{array}$ & \% \\
\hline Perempuan & 33 & 48,53 \\
\hline Laki-laki & 35 & 51,47 \\
\hline Jumlah & 68 & 100 \\
\hline
\end{tabular}

(Sumber : Penelitian 2012)

Berdasarakan tabel 5.6 di atas, distribusi jenis kelamin responden paling banyak terdapat pada jenis kelamin laki-laki yaitu sebanyak 35 orang $(51,47 \%)$, dan umur responden yang paling sedikit terdapat pada jenis kelamin perempuan sebanyak 33 orang $(48,53 \%)$.

3. Pekerjaan

Adapun gambaran distribusi frekuensi responden menurut pendidikan dapat dilihat dalam tabel di bawah ini :
Tabel 5.7 Distribusi $\quad$ Frekuensi Menurut Pekerjaan

\begin{tabular}{|l|c|c|}
\hline \multicolumn{1}{|c|}{ Kategori } & $\begin{array}{c}\text { Frekuensi } \\
\text { (Orang) }\end{array}$ & $\boldsymbol{\%}$ \\
\hline Tidak Bekerja & 22 & 32,35 \\
\hline Petani & - & - \\
\hline Buruh & - & - \\
\hline Wiraswasta & 41 & 60,29 \\
\hline Pegawai Swasta & - & - \\
\hline Pegawai Negeri & 5 & 7,36 \\
\hline Jumlah & 68 & 100 \\
\hline
\end{tabular}

(Sumber : Penelitian 2012)

Berdasarakan tabel 5.7 di atas, distribusi pekerjaan responden paling banyak terdapat pada pekerjaan wiraswasta yaitu sebanyak 41 orang $(60,29 \%)$, dan pekerjaan responden yang paling sedikit terdapat pada pekerjaan pegawai negeri sebanyak 5 orang $(7,36 \%)$.

1. Pendidikan

Adapun gambaran distribusi frekuensi responden menurut pendidikan dapat dilihat dalam tabel di bawah ini :

Tabel 5.8 Distribusi Frekuensi Menurut Pendidikan

\begin{tabular}{|l|c|c|}
\hline \multicolumn{1}{|c|}{ Kategori } & $\begin{array}{c}\text { Frekuensi } \\
\text { (Orang) }\end{array}$ & $\boldsymbol{\%}$ \\
\hline Tamat SD & 37 & 54,41 \\
\hline Tamat SMP & 13 & 19,12 \\
\hline Tamat SMA & 13 & 19,12 \\
\hline Perguruan Tinggi & 5 & 7,35 \\
\hline Jumlah & 68 & 100 \\
\hline
\end{tabular}

(Sumber : Penelitian 2012)

Berdasarkan tabel 5.8 di atas dapat diketahui bahwa responden yang paling banyak berpendidikan tamatan SD sebanyak 37 orang $(54,41 \%)$, dan yang paling sedikit adalah tamatan perguruan tinggi yaitu sebanyak 5 orang $(7,35 \%)$.

2. Pendapatan

Karakteristik responden menurut pendapatan dapat dilihat dalam tabel 5.9 
Tabel 5.9 Distribusi Frekuensi Menurut Pendapatan

\begin{tabular}{|l|c|c|}
\hline \multicolumn{1}{|c|}{ Kategori } & $\begin{array}{c}\text { Frekuensi } \\
\text { (Orang) }\end{array}$ & $\%$ \\
\hline$<$ Rp.605.000,- & 37 & 54,41 \\
\hline $\begin{array}{l}\text { Rp.605.000,- - } \\
\text { juta }\end{array}$ & 13 & 19,12 \\
\hline$>1$ juta & 18 & 26,47 \\
\hline Jumlah & 68 & 100 \\
\hline
\end{tabular}

(Sumber : Penelitian 2012)

Berdasarkan tabel 5.9 di atas dapat diketahui bahwa responden yang paling banyak berpendapatan <Rp.605.000,- sebanyak 37 orang $(54,41 \%)$, dan yang paling sedikit berpendapatan Rp.605.000,- - 1 juta yaitu sebanyak 13 orang $(19,12 \%)$.

3. Jumlah Responden yang Berkunjung dan yang Tidak Berkunjung ke Posbindu

Hasil penelitian diperoleh data bahwa sebagian besar responden yang tidak berkunjung ke Posbindu, untuk lebih lengkapnya dapat dilihat pada tabel 5.10 berikut :

Tabel 5.10 Distribusi Frekuensi Menurut Kunjungan

\begin{tabular}{|l|c|c|}
\hline \multicolumn{1}{|c|}{ Kategori } & $\begin{array}{c}\text { Frekuensi } \\
\text { (Orang) }\end{array}$ & $\boldsymbol{\%}$ \\
\hline Yang Berkunjung & 7 & 10,3 \\
\hline $\begin{array}{l}\text { Yang Tidak } \\
\text { Berkunjung }\end{array}$ & 61 & 89,7 \\
\hline Jumlah & 68 & 100 \\
\hline
\end{tabular}

(Sumber : Penelitian 2012)

Berdasarkan tabel 5.10 dapat diketahui bahwa jumlah responden yang tidak berkunjung ke Posbindu sebanyak 61 orang $(10,3 \%)$ dan yang berkunjung sebanyak 7 orang $(10,3 \%)$.

Faktor-Faktor yang Mempengaruhi Kunjungan Lanjut Usia untuk Berkunjung ke Posbindu Tawang Sari di Wilayah Kerja Puskesmas Tawang Kota Tasikmalaya Tahun 2012

Hasil penelitian yang dilakukan terhadap 68 responden lanjut usia menurut pengetahuan, sikap, tersedianya sarana pelayanan kesehatan, kemudahan untuk mencapai fasilitas kesehatan, sikap dan perilaku petugas kesehatan dapat dilihat pada tabel berikut :

\section{Pengetahuan}

Hasil penelitian diperoleh data bahwa sebagian besar pengetahuan dari responden memiliki pengetahuan yang baik, untuk lebih lengkapnya dapat dilihat pada tabel berikut

Tabel 5.11 Distribusi Frekuensi

Karakteristik Responden

Berdasarkan Pengetahuan

\begin{tabular}{|l|c|c|}
\hline Kategori & $\begin{array}{c}\text { Frekuensi } \\
\text { (Orang) }\end{array}$ & \% \\
\hline Baik & 27 & 39,7 \\
\hline Cukup & 41 & 60,3 \\
\hline Kurang & - & - \\
\hline Jumlah & 68 & 100 \\
\hline
\end{tabular}

(Sumber : Penelitian 2012)

Berdasarkan tabel 5.11 dapat diketahui bahwa jumlah responden yang mempunyai pengetahuan baik sebanyak 27 orang $(39,7 \%)$, pengetahuan cukup 41 orang $(60,3 \%)$.

2. Sikap

Hasil penelitian diperoleh data bahwa sebagian besar sikap dari responden memiliki sikap yang baik, untuk lebih lengkapnya dapat dilihat pada tabel 5.12 berikut :

Tabel 5.12 Distribusi Frekuensi Karakteristik Responden Berdasarkan Sikap

\begin{tabular}{|l|c|c|}
\hline Kategori & $\begin{array}{c}\text { Frekuensi } \\
\text { (Orang) }\end{array}$ & $\boldsymbol{\%}$ \\
\hline Baik & 46 & 67,65 \\
\hline Cukup & 22 & 32,35 \\
\hline Kurang & - & - \\
\hline Jumlah & 68 & 100 \\
\hline
\end{tabular}

(Sumber : Penelitian 2012)

Berdasarkan tabel 5.12 dapat diketahui bahwa jumlah responden yang mempunyai sikap baik sebanyak 46 orang $(67,65 \%)$, pengetahuan cukup 22 orang $(32,35 \%)$.

3. Tersedianya sarana pelayanan kesehatan

Hasil penelitian diperoleh data bahwa sebagian besar jawaban dari responden tentang tersedianya sarana pelayanan kesehatan menilai kurang memuaskan, untuk lebih lengkapnya dapat dilihat pada tabel 5.13 berikut : 
Tabel 5.13 Distribusi Frekuensi Karakteristik Responden Berdasarkan Tersedianya Sarana Pelayanan Kesehatan

\begin{tabular}{|l|c|c|}
\hline \multicolumn{1}{|c|}{ Kategori } & $\begin{array}{c}\text { Frekuensi } \\
\text { (Orang) }\end{array}$ & $\boldsymbol{\%}$ \\
\hline $\begin{array}{l}\text { Kurang } \\
\text { Memuaskan }\end{array}$ & 68 & 100 \\
\hline Memuaskan & - & - \\
\hline Jumlah & 68 & 100 \\
\hline
\end{tabular}

(Sumber : Penelitian 2012)

Berdasarkan tabel 5.13 dapat diketahui bahwa jumlah responden yang menilai tentang tersedianya sarana pelayanan kesehatan adalah kurang memuaskan sebanyak 100 orang (100\%).

4. Sikap dan perilaku petugas kesehatan

Hasil penelitian diperoleh data bahwa sebagian besar jawaban dari responden tentang sikap dan perilaku petugas

5. Tabulasi Silang antara Pengetahuan dengan Kunjungan

Tabulasi silang antara pengetahuan dengan kunjungan yang mempengaruhi kesehatan memuaskan, untuk lebih lengkapnya dapat dilihat pada tabel berikut :

Tabel 5.14 Distribusi Frekuensi

Karakteristik Responden

Berdasarkan Sikap dan Perilaku Petugas Kesehatan

\begin{tabular}{|l|c|c|}
\hline \multicolumn{1}{|c|}{ Kategori } & $\begin{array}{c}\text { Frekuensi } \\
\text { (Orang) }\end{array}$ & $\boldsymbol{\%}$ \\
\hline Memuaskan & 68 & 100 \\
\hline Kurang Memuaskan & - & - \\
\hline Jumlah & 68 & 100 \\
\hline
\end{tabular}

(Sumber : Penelitian 2012)

Berdasarkan tabel 5.14 dapat diketahui bahwa jumlah responden yang menilai tentang sikap dan perilaku petugas kesehatan adalah memuaskan sebanyak 68 orang $(100 \%)$.

kunjungan lanjut usia untuk berkunjung ke Posbindu Tawangsari di Wilayah Kerja Puskesmas Tawang Kota Tasikmalaya Tahun 2012 :

Tabel 5.15 Tabulasi Silang antara Pengetahuan dengan Kunjungan

\begin{tabular}{|c|c|c|c|c|c|c|c|c|}
\hline \multirow{3}{*}{ Kunjungan } & \multicolumn{8}{|c|}{ Pengetahuan } \\
\hline & \multicolumn{2}{|c|}{ Baik } & \multicolumn{2}{|c|}{ Cukup } & \multicolumn{2}{|c|}{ Kurang } & \multirow{2}{*}{ Jml } & \multirow{2}{*}{$\%$} \\
\hline & Jml & $\%$ & Jml & $\%$ & Jml & $\%$ & & \\
\hline Berkunjung & 6 & 8,8 & 1 & 1,5 & 0 & 0 & 7 & 10,3 \\
\hline $\begin{array}{l}\text { Tidak } \\
\text { Berkunjung }\end{array}$ & 21 & 30,9 & 40 & 58,8 & 0 & 0 & 61 & 89,7 \\
\hline Total & 27 & 39,7 & 41 & 60,3 & $\mathbf{0}$ & $\mathbf{0}$ & 68 & 100 \\
\hline
\end{tabular}

(Sumber : Penelitian 2012)

Berdasarkan tabel 5.15 dapat diketahui bahwa jumlah responden yang berkunjung mempunyai pengetahuan baik sebanyak 6 orang $(8,8 \%)$, jumlah responden yang tidak berkunjung mempunyai pengetahuan baik sebanyak 21 orang

6. Tabulasi Silang antara Sikap dengan Kunjungan

Tabulasi silang antara sikap dengan kunjungan yang mempengaruhi
$(30,9 \%)$, jumlah responden yang berkunjung mempunyai pengetahuan cukup sebanyak 1 orang (1,5\%) dan jumlah responden yang tidak berkunjung mempunyai pengetahuan cukup sebanyak 40 orang $(58,8 \%)$.

kunjungan lanjut usia untuk berkunjung ke Posbindu Tawangsari di Wilayah Kerja Puskesmas Tawang Kota Tasikmalaya Tahun 2012 : 
Tabel 5.16 Tabulasi Silang antara Sikap dengan Kunjungan

\begin{tabular}{|c|c|c|c|c|c|c|c|c|}
\hline \multirow{3}{*}{ Kunjungan } & \multicolumn{8}{|c|}{ Sikap } \\
\hline & \multicolumn{2}{|c|}{ Baik } & \multicolumn{2}{|c|}{ Cukup } & \multicolumn{2}{|c|}{ Kurang } & \multirow{2}{*}{ Jml } & \multirow{2}{*}{$\%$} \\
\hline & Jml & $\%$ & Jml & $\%$ & $\mathbf{J m l}$ & $\%$ & & \\
\hline Berkunjung & 4 & 5,9 & 3 & 4,4 & 0 & 0 & 7 & 10,3 \\
\hline $\begin{array}{l}\text { Tidak } \\
\text { Berkunjung }\end{array}$ & 42 & 61,8 & 19 & 27,9 & 0 & 0 & 61 & 89,7 \\
\hline Total & 46 & 67,7 & 22 & 32,3 & $\mathbf{0}$ & $\mathbf{0}$ & 68 & 100 \\
\hline
\end{tabular}

(Sumber : Penelitian 2012)

Berdasarkan tabel 5.16 dapat diketahui bahwa jumlah responden yang berkunjung mempunyai sikap baik sebanyak 4 orang $(5,9 \%)$, jumlah responden yang tidak berkunjung mempunyai sikap baik sebanyak 42 orang $(61,8 \%)$, jumlah responden yang berkunjung mempunyai sikap yang cukup sebanyak 3 orang $(4,4 \%)$ dan jumlah responden yang tidak berkunjung mempunyai sikap yang cukup sebanyak 19 orang $(27,9 \%)$.

Tabel 5.17 Tabulasi Silang antara Tersedianya Pelayanan Kesehatan dengan Kunjungan

\begin{tabular}{|c|c|c|c|c|c|c|}
\hline \multirow{3}{*}{ Kunjungan } & \multicolumn{4}{|c|}{ Tersedianya Sarana Yankes } & \multirow{3}{*}{ Jumlah } & \multirow{3}{*}{$\%$} \\
\hline & \multicolumn{2}{|c|}{ Tersedia } & \multicolumn{2}{|c|}{ Tidak Tersedia } & & \\
\hline & Jml & $\%$ & Jml & $\%$ & & \\
\hline Berkunjung & 0 & 0 & 7 & 10,3 & 7 & 10,3 \\
\hline Tidak Berkunjung & 0 & 0 & 61 & 89,7 & 61 & 89,7 \\
\hline Total & $\mathbf{0}$ & $\mathbf{0}$ & 68 & 100 & 68 & 100 \\
\hline
\end{tabular}

(Sumber : Penelitian 2012)
Berdasarkan tabel 5.17 dapat diketahui bahwa jumlah responden yang berkunjung menilai tentang tersedianya sarana pelayanan kesehatan tidak memuaskan sebanyak 7 orang $(10,3 \%)$ dan jumlah responden yang tidak berkunjung menilai tentang tersedianya sarana pelayanan kesehatan tidak memuaskan sebanyak 61 orang $(89,7 \%)$.
7. Tabulasi Silang antara Tersedianya Pelayanan Kesehatan dengan Kunjungan

Tabulasi silang antara Tersedianya Pelayanan Kesehatan dengan Kunjungan yang mempengaruhi kunjungan lanjut usia untuk berkunjung ke Posbindu Tawangsari di Wilayah Kerja Puskesmas Tawang Kota Tasikmalaya Tahun 2012 :
8. Tabulasi Silang antara Sikap dan Perilaku Petugas Kesehatan dengan Kunjungan

Tabulasi silang antara sikap dan perilaku petugas kesehatan dengan kunjungan yang mempengaruhi kunjungan lanjut usia untuk berkunjung ke Posbindu Tawangsari di Wilayah Kerja Puskesmas Tawang Kota Tasikmalaya Tahun 2012: 
Tabel 5.18 Tabulasi Silang antara Sikap dan Perilaku Petugas Kesehatan dengan Kunjungan

\begin{tabular}{|c|c|c|c|c|c|c|}
\hline \multirow{3}{*}{ Kunjungan } & \multicolumn{4}{|c|}{$\begin{array}{c}\text { Sikap dan Perilaku Petugas } \\
\text { Kesehatan }\end{array}$} & \multirow{3}{*}{ Jumlah } & \multirow{3}{*}{$\%$} \\
\hline & \multicolumn{2}{|c|}{ Memuaskan } & \multicolumn{2}{|c|}{$\begin{array}{c}\text { Tidak } \\
\text { Memuaskan } \\
\end{array}$} & & \\
\hline & Jml & $\%$ & Jml & $\%$ & & \\
\hline Berkunjung & 7 & 10,3 & 0 & 0 & 7 & 10,3 \\
\hline Tidak Berkunjung & 61 & 89,7 & 0 & 0 & 61 & 89,7 \\
\hline Total & 68 & 100 & $\mathbf{0}$ & $\mathbf{0}$ & 68 & 100 \\
\hline
\end{tabular}

(Sumber : Penelitian 2012)

Berdasarkan tabel 5.18 dapat diketahui bahwa jumlah responden yang berkunjung menilai tentang dengan sikap dan perilaku petugas kesehatan memuaskan sebanyak 7

\section{E. Pembahasan}

\section{Pengetahuan}

Hasil penelitian ini yaitu faktor-faktor yang mempengaruhi perilaku lanjut usia untuk berkunjung ke posyandu tawangsari di wilayah kerja puskesmas tawang tasikmalaya tahun 2012 menunjukan bahwa yang memiliki pengetahuan yang cukup sebanyak 41 orang $(60,3 \%)$, hal ini dipengaruhi oleh banyaknya informasi yang didapatkan tentang kesehatan, sedangkan yang memiliki pengetahuan baik sebanyak 27 orang $(39,7 \%)$, hal ini dipengaruhi oleh cukupnya informasi yang didapatkan tentang kesehatan.

Dari data tersebut dapat disimpulkan bahwa pengetahuan responden yang tergolong baik dan tidak akan mempengaruhi pada pemahaman mereka terhadap perilaku lanjut usia dalam melaksanakan kunjungan ke Posbindu untuk memeriksakan kesehatannya.

Hal ini sesuai dengan teori bahwa pengetahuan merupakan hasil dari tahu dan ini terjadi setelah orang melakukan penginderaan terhadap suatu objek tertentu. Pengetahuan atau kognitif merupakan domain yang sangat penting dalan tindakan seseorang (overt behaviour) (Notoatmodjo, 2003).

orang $(10,3 \%)$ dan jumlah responden yang tidak berkunjung menilai tentang dengan sikap dan perilaku petugas kesehatan memuaskan sebanyak 61 orang $(89,7 \%)$.

Pengetahuan adalah merupakan hasil dari tahu dan ini terjadi setelah orang melakukan penginderaan terhadap objek tertentu. Penginderaan terhadap objek terjadi melalui panca indera manusia, yaitu : penglihatan, pendengaran, penciuman, rasa dan raba. Sebaian besar pengetahuan manusia diperoleh melalui mata dan telinga (Notoatmodjo : 2003).

Pengetahuan diperoleh dengan tujuan untuk menjawab semua permasalahan kehidupan sehari-hari yang di alami oleh manusia dan untuk di gunakan dalam menawarkan berbagai kemudahan.

2. Sikap

Hasil penelitian ini sesuai dengan sikap menunjukan bahwa yang memiliki sikap yang baik sebanyak 46 orang $(67,65 \%)$, sedangkan yang memiliki sikap cukup sebanyak 22 orang $(32,35 \%)$.

Dengan demikian sikap yang baik akan mendorong seseorang untuk aktif dalam kegiatan posyandu. Hal ini tidak sesuai dengan teori Dep Kes RI, dalam Mujiono (2004), yaitu sikap pada hakekatnya merupakan kondisi kejiwaan, perasaan dan keinginan seseorang, sehingga hal tersebut berpengaruh pada perilaku serta akhirnya perbuatan yang diwujudkannya. Sikap juga dikatakan 
sebagai suatu respon evaluatif, yang hanya akan timbul apabila individu dihadapkan pada suatu stimulus yang menghendaki adanya reaksi individual. Akan tetapi kebanyakan para lanjut usia tidak berkunjung ke Posbindu Tawangsari.

Sikap adalah cara menempatkan atau membawa diri atau cara merasakan, jalan pikiran dan perilaku. Melalui sikap, kita memahami proses kesadaran yang menentukan tindakan yang mungkin dilakukan individu dalam kehidupan sosialnya. Jadi sikap adalah predisposisi untuk melakukan atau tidak melakukan suatu perilaku tertentu, sehingga sikap bukan hanya kondisi internal psikologis yang murni dari diri individu (purely psychic inner state), tapi sikap lebih merupakan proses kesadaran yang sifatnya individual. Artinya proses ini terjadi secara subjektif dan unik pada diri setiap individu. Keunikan ini dapat terjadi oleh adanya perbedaan individual yang berasal dari nila-nilai dan norma yang ingin dipertahankan dan dikelola oleh individu (Coser, dalam www.bolender.com).

Sikap merupakan reaksi atau respon seseorang yang masih tertutup terhadap suatu stimulus atau obyek. Dari berbagai batasan tentang sikap dapat disimpulkan bahwa manisfestasi sikap itu tidak dapat langsung dilihat, tetapi hanya dapat ditafsirkan terlebih dahulu dari perilaku yang tertutup. Sikap secara nyata menunjukan konotasi adanya kesesuaian reaksi terhadap stimulus tertentu.

Notoatmodjo mengatakan bahwa Newcomb salah seorang ahli psikologi sosial menyatakan bahwa sikap itu merupakan tertentu. Sikap belum merupakan suatu tindakan atau aktifitas, akan tetapi merupakan predisposisi tindakan atau perilaku.

Jadi hal yang mempengaruhi para lanjut usia tidak berkunjung ke Posbindu adalah kebanyakan para lanjut usia masih bekerja, jadi para lanjut usia merasa dirinya masih sehat dan tidak perlu untuk memeriksakan kesehatannya.

3. Tersedianya sarana pelayanan kesehatan

Berdasarkan hasil penelitian dapat diketahui tersedianya sarana pelayanan kesehatan di posyandu bahwa paling besar penilaian menurut responden tentang tersedianya sarana pelayanan kesehatan yang diberikan kurang memuaskan yaitu sebanyak 68 orang $(100 \%)$, hal ini dipengaruhi oleh kurangnya sarana pelayanan kesehatan yang berada di Posbindu.

Dari data tersebut dapat ditarik kesimpulan bahwa pada umumnya tersedianya sarana pelayanan kesehatan yang dapat dimanfaatkan oleh para lanjut usia sangat mempengaruhi para lanjut usia untuk berkunjung ke Posbindu.

Menurut Green (1980) yang dikutif oleh Notoatmodjo (2012) faktor pendukung (enabling factor) yang terwujud dalam lingkungan fisik, tersedianya fasilitas-fasilitas atau saranasarana kesehatan. Misalnya puskesmas, alat-alat kesehatan dan alat-alat laboratorium.

Langkah-langkah untuk memperkuat pelayanan kesehatan dalam konteks peningkatan derajat kesehatan masyarakat, antara lain dengan menentukan cakupan pelayanan dan fasilitas pelayanan yang dilibatkan, menentukan standar pelayanan yang akan disediakan dan batas tanggung jawab penatalaksanaan kasus di setiap jenjang pelayanan, melatih keterampilan klinik untuk pelayanan kepada para lanjut usia melakukan pemantauan dan memberikan dukungan pemecahan yang dihadapi lanjut usia, serta mengembangkan pelayanan yang berorientasi pada kebutuhan klien yang mampu melakukan kegiatan luar gedung dalam bentuk komunikasi, informasi dan edukasi. 
Selain kurangnya sarana pelayanan kesehatan di Posbindu hal yang mempengaruhi para lanjut usia tidak berkunjung ke Posbindu adalah karakteristik usia lanjut kebanyakan masih ada pada usia produktif dan masih bekerja sehingga para lanjut usia tidak sempat untuk berkunjung ke Posbindu.

\section{Sikap dan perilaku petugas kesehatan}

Berdasarkan hasil penelitian dapat diketahui bahwa lanjut usia menilai sikap dan perilaku petugas kesehatan paling banyak adalah memuaskan sebanyak 68 orang (100\%). Dari data tersebut dapat disimpulkan bahwa sikap dan perilaku petugas kesehatan yang memuaskan akan mempengaruhi pada para lanjut usia dalam melakukan kunjungan ke Posbindu.

Hal ini tidak sesuai dengan teori, menurut kamus Bahasa Indonesia oleh W.J.S. Poerwodarminto, sikap adalah perbuatan yang didasari oleh keyakinan berdasarkan norma-norma yang ada di masyarakat dan biasanya norma agama. Namun demikian perbuatan yang akan dilakukan manusia biasanya tergantung apa permasalahannya serta benar-benar berdasarkan keyakinan atau kepercayaannya masing-masing.

Salah satu tugas pelaksana program kesehatan di Posbindu dan di Puskesmas

\section{F. Simpulan dan saran}

Simpulan penelitian ini $60,3 \%$ pengetahuan lanjut usia tentang Posbindu termasuk kategori cukup , $67,65 \%$ sikap lanjut usia terhadap Posbindu termasuk kategori baik, $100 \%$ responden menyatakan ketersedianya sarana pelayanan kesehatan di Posbindu termasuk kategori kurang memuaskan serta 100\% Responden menyatakan bahwa Gambaran sikap dan perilaku petugas kesehatan Posbindu termasuk kategori memuaskan. yaitu memberikan pelayanan berupa pemeriksaan aktivitas kegiatan seharihari meliputi kegiatan dasar dalam kehidupan, seperti makan/minum, berjalan, mandi, berpakaian, naik turun tempat tidur, buang air besar/kecil dan sebagainya.

Pelaksana kesehatan harus menyusun strategi agar sasaran yang ada di wilayah kerjanya memperoleh pelayanan kesehatan seperti yang diharapkan. Untuk itu perlu pengelolaan secara aktif mulai dari perencanaan, pelaksanaan dan evaluasi. Seorang bidan tidak hanya harus menguasai keterampilan teknis klinis, tetapi sangat diharapkan mampu berkomunikasi dan melakukan konseling yang baik. Kualitas komunikasi/konseling yang rendah, sekalipun ia secara teknis terampil, maka pelayanan yang diberikan kepada klien tidak akan optimal bahkan mungkin rendah (IBI Jawa Barat $2003: 1$ ).

Sikap dan perilaku petugas kesehatan menurut para lanjut usia adalah memuaskan. Hal ini tidak mempengaruhi para lanjut usia untuk berkunjung ke Posbindu, karena faktor penyebab tidak berkunjung ke Posbindu adalah kebanyakan para lanjut usia masih bekerja, jadi para lanjut usia merasa dirinya masih sehat dan tidak perlu untuk memeriksakan kesehatannya.

Diharapkan dapat memanfaatkan fasilitas kesehatan sebaik mungkin. Sehingga berkunjung ke posyandu secara tertatur dan rutin ke petugas kesehatan atau tempat pelayanan kesehatan dapat mengetahui kesehatannya.

Diharapkan lebih meningkatkan pembinaan dan pelatihan tenaga kesehatan di posyandu dan manajemen terutama dalam tahap perencanaan, pelaksanaan dan evaluasi program. Dari semua tahapan di atas harus melibatkan 
semua komponen yang ada di Wilayah Kerja Puskesmas Tawang seperti pemerintah setempat, tokoh masyarakat,

\section{G. Referensi}

Arikunto, S. (2006). Prosedur Penelitian Suatu Pendekatan Praktik Edisi Revisi VI, Jakarta : Rineka Cipta

Brooker, Chris. (2008). Enslikopedia Keperawatan . jakarta:EGC

Dharma, Kelana Kusuma. (2011). Metodologi Penelitian Keperawatan, Panduan Melaksanakan dan Menerapkan Hasil Penelitian.Jakarta:Trans Info Media

Gibney, Michael J. (2008). Gizi Kesehatan Masyarakat. Jakarta: EGC

Kristinawati, Lidwina Ratna Budi. (2011). Pengaruh Tingkat Kemandirian Terhadap Kualitas Hidup Pada Lansia di Posbindu Lansia Pergeri RW 02.Diunduh pada 29 Oktober 2012 dari http://www.library.upnvj.ac.id /pdf/5FKS1KEDOKTERAN/ 207311038/BAB\%20IV.pdf

Lestari, Junika Suci. (2012).Gambaran Pengetahuan Keluarga dalam Pemberian Gizi Pada Lansia di Desa Sidorejo Kecamatan Siantar. Diunduh pada 4 November 2012 dari http://repository.usu.ac.id/bitst ream/123456789/32885/4/Cha pter\%20II.pdf

Maryam, R. Siti, dkk. (2008). Mengenal Usia Lanjut dan Perawatannya. Jakarta : Salemba

Maryam, Siti dkk. (2010). Asuhan Keperawatan Pada Lansia.Jakarta : Trans Info Medika

Metodologi Penelitian Kesehatan. Jakarta: Rineka Cipta ulama, dukun bayi dan bidan serta komponen lainnya.

Soekijdo. (2007). Kesehatan Masyarakat Ilmu \& Seni. Jakarta : Rineka Cipta Soekijdo. (2010). Metodologi Penelitian Kesehatan. Jakarta: Rineka Cipta.

Nugroho, Wahyudi. (2008). Keperawatan Gerontik \& Geriatrik. Jakarta : EGC 